\title{
Corticosteroid-induced myopathy in spinal cord injury patients: a role for anticatabolic agents?
}

\author{
Spinal Cord (2006) 44, 263-264. doi:10.1038/sj.sc.3101814; published online 20 September 2005
}

We read with interest the article by Qian et al on 'High-dose methylprednisolone may cause myopathy in acute spinal cord injury patients.' The authors presented interesting data on EMG and muscle biopsies, which demonstrated acute myopathy in patients after receiving methylprednisolone for spinal cord injury. Conflicts over the use of methylprednisolone for spinal cord injury concern the risk-to-benefit ratio. ${ }^{2,3}$ A study by the co-workers of Qian et al demonstrated that methylprednisolone administered to patients with spinal cord injury upon admission and during the operative procedure significantly increased risk for complications as compared to a single dose upon admission. ${ }^{4}$ Corticosteroids are routinely utilized in neurosurgery patients for their inherent ability to decrease edema. ${ }^{5}$ Corticosteroids have been shown to have a multitude of deleterious effects on other organ systems. ${ }^{2-3}$ A few cases of catastrophic immunosuppression have been reported with routine doses of corticosteroids in the postoperative period. ${ }^{2,3,6}$ We have previously reported on the use of Oxandrin (BTG Pharmaceuticals, NJ, USA), which is indicated to combat the deleterious effects of corticosteroids. ${ }^{7,8}$ Oxandrin has anticatabolic and anabolic properties by binding to the androgen receptor and initiating an anabolic cascade of tissue building and repair and it is anticatabolic through the weak competitive binding to the corticosteroid receptor thus buffering the catabolic cascade. ${ }^{9}$ One might question, would the Oxandrin inhibit the beneficial effects on cerebral and spinal cord edema, and through our own clinical experience it has not been an issue.

Of interest is the recent evidence suggesting that progesterone may be an alternative to corticosteroids in spinal cord injury and traumatic brain injury. ${ }^{10,11}$ Progesterone was found to have antiapoptotic and antiastrogliotic effects on the brain and led to improved cognitive performance as compared to control animals with traumatic brain injury. ${ }^{10}$ In addition, progesterone has shown to be neuroprotective in spinal cord injury in animals. ${ }^{11}$ Are the effects of progesterone solely through the progesterone receptor or is it also binding to the androgen receptor? Progesterone has an affinity to the androgen receptor and thus the actual benefits may be, in part, through the androgen receptor. ${ }^{9}$ We commend Qian et al on their fine work and propose to the authors to add a third group to the study which would incorporate Oxandrin and methylprednisolone to determine if the anabolic/anticatabolic effects of Oxandrin may prevent myopathy from occurring.

RD Dickerman, AM Joseph and MT Bennett Department of Neurosurgery, North Texas Neurosurgical Associates, 3001 Communications Parkway, Suite 1027, Plano, TX 75093, USA

\section{References}

1 Qian T, Guo X, Levi AD, Vanni S, Shebert RT, Sipski ML. High-dose methylprednisolone may cause myopathy in acute spinal cord injury patients. Spinal Cord 2005; 43: 199-203.

2 DeMaria EJ, Reichman W, Kenney PR, Armitage JM, Gann DS. Septic complications of corticosteroid administration after central nervous system trauma. Ann Surg 1985; 202: 248-252.

3 Russian DA, Levine SJ. Pneumocystitis carinii pneumonia in patients without HIV infection. Am J Med Sci 2001; 321: 56-65.

4 Molano Mdel R, Broton JG, Bean JA, Calancie B. Complications associated with the prophylactic use of methylprednisolone during surgical stabilization after spinal cord injury. J Neurosurg 2002; 96: 267-272.

5 Boumpas DT. Glucocorticoid therapy for immunemediated diseases: basic and clinical correlates. Ann Intern Med 1993; 119: 1198-1208.

6 Dickerman RD, Stevens QE, Schneider SJ. Sudden death secondary to fulminant intracranial aspergillosis in a healthy teenager after posterior fossa surgery: the role of corticosteroids and prophylactic recommendations. J Neurosurg Sci 2004; 48: 87-89.

7 Dickerman RD, Schneider SJ, Stevens QE, Matarese NM, Decker RE. Prophylaxis to avert exacerbation/relapse of multiple sclerosis in affected patients undergoing surgery. Surgical observations and recommendations. J Neurosurg Sci 2004; 48: 135-137.

8 Spungen AM, Koehler KM, Modeste-Duncan R, Rasul M, Cytryn AS, Bauman WA. 9 clinical cases of nonhealing pressure ulcers in patients with spinal cord injury treated with an anabolic agent: a therapeutic trial. Adv Skin Wound Care 2001; 14: 139-144.

9 Dickerman RD, Jaikumar S. The hiccup reflex arc and persistent hiccups with high-dose anabolic steroids: Is the brainstem the steroid-responsive locus? Clin Neuropharmacol 2001; 24: 62-64. 
10 Djebaili M, Guo Q, Pettus EH, Hoffman SW, Stein DG. The neurosteroids progesterone and allopregnanolone reduce cell death, gliosis, and functional deficits after traumatic brain injury in rats. $J$ Neurotrauma 2005; 22: 106-118.
11 Gonzalez SL, Labombarda F, Gonzalez Deniselle MC, Guennoun R, Schumacher M, De Nicola AF. Progesterone up-regulates neuronal brain-derived neurotrophic factor expression in the injured spinal cord. Neuroscience 2004; 125: $605-614$. 